\title{
Fantastische Herbstfärbung 2015
}
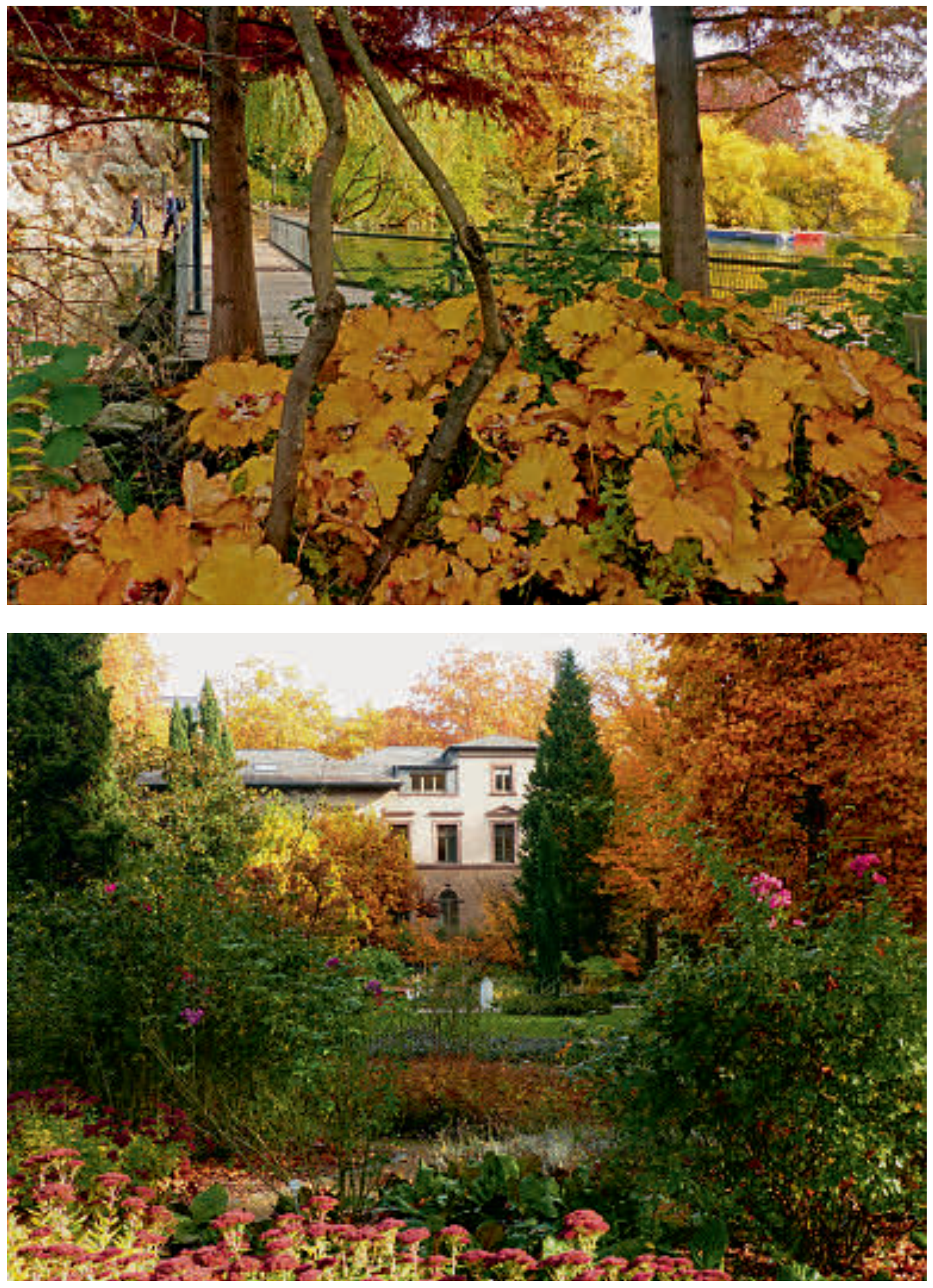

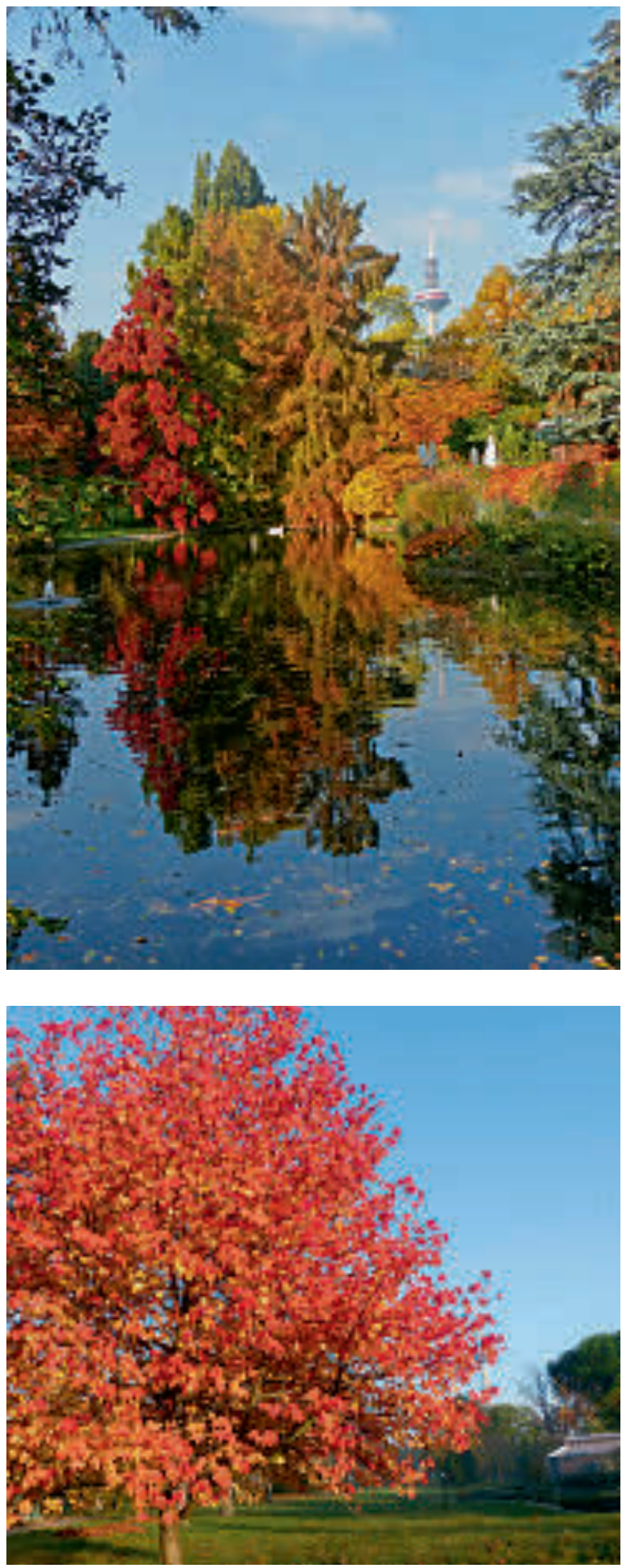

Abb. 1 (Seite 166 oben): Am Steg über den Großen Weiher.

Abb. 2 (Seite 166 unten): Blick auf das Direktionsgebäude.

Abb. 3 (oben links): Am Kleinen Weiher.

Abb. 4 (oben rechts): Spottnuss vor dem Blütenhaus.

Abb. 5 (unten links): Amberbaum an der Steppenwiese.

Abb. 6 (unten rechts): Am Kinderkiosk.
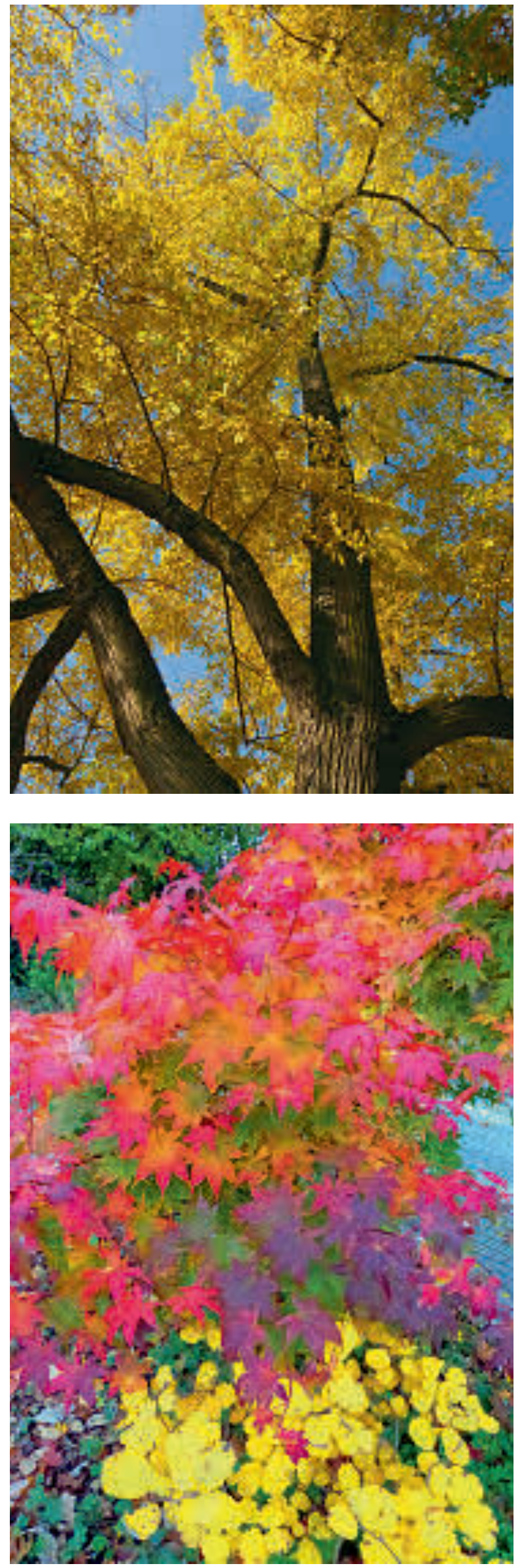